\title{
Estimating fertility rates using the ONS Longitudinal Study - what difference does the inclusion of non-continually resident members make?
}

James Robards, Ann Berrington and Andrew Hinde

Southampton Statistical Sciences Research Institute, University of Southampton

\section{Abstract}

Among datasets available for fertility research in England and Wales, the Office for National Statistics (ONS) Longitudinal Study (LS) is unique in its construction and scale. The large number of individuals who are part of the study means that it is an important dataset for estimating fertility trends in England and Wales by age and parity. This article uses the LS to estimate age-specific fertility rates (ASFRs) for England and Wales between 1991 and 2001. This necessitates great care to ensure that the exposure to risk of birth for female LS members is fully understood. To achieve this, two forms of residential history are defined consistent cases where the residential information for the LS member is potentially complete for the whole decade and inconsistent cases where there is certainly some form of incompleteness in the residence information. By considering 'all consistent cases', that is both the continuously resident plus those who are not continuously resident but appear to have a complete residential history, we obtain ASFRs which are slightly lower than official statistics figures, but closer to these official figures than ASFRs produced when restricting the sample to LS members who remain continuously resident between 1991 and 2001. The fertility of those consistent cases who are not continuously resident is substantially higher than the rates of continuously resident cases. 


\section{Introduction}

Since its inception, the Office for National Statistics (ONS) Longitudinal Study (LS) has been used for a wide variety of demographic research (Goldring and Newman, 2010). The LS is attractive for fertility research for a number of reasons: the large sample size (over one million members at one point or another) in combination with socio-economic information collected from the decennial census means that analyses of age and parity-specific fertility trends (Rendall and Smallwood, 2003) can be made for different population sub-groups. Births to LS members are linked via the vital registration system and the linkage quality has improved from the first two decades of the study (ONS, 2008). Therefore reporting errors do not affect the recording of births to LS members as have been noted in some retrospectively reported fertility histories (Ní Bhrolcháin et al., 2011; Murphy, 2009). The LS covers the period since the 1971 Census and hence can provide data for a considerable period.

While there is now a high degree of certainty in the linkage of births to LS members (ONS, 2008), the denominators required for calculating fertility rates (or the population exposed to the risk of childbearing) outside of census years is more difficult. Crucial to the operation of the LS is the National Health Service Central Register (NHSCR) which provides information on new entrants to (immigrations) and exits from (termed embarkations) England and Wales through the link between the study and General Practitioner (GP) registration status on the NHSCR. In order to identify if an LS member is resident in a single year it is necessary to consider the full history of embarkations and re-entries to the LS which are recorded from the NHSCR. If the wrong denominator is used then exposure to risk of birth could be granted to women who are not resident in England and Wales or too limited exposure granted to women ordinarily resident in England and Wales.

It is for this reason that this article focuses on identifying LS members according to their residence between the 1991 and 2001 censuses. Furthermore the article demonstrates differences in fertility rates when different samples are selected according to their residence trajectories. Most fertility research using the LS has selected members of the study who are continuously resident, defined as being resident at successive census dates and showing no recorded embarkation or re-entry on the NHSCR during the intervening period (Portanti and Whitworth, 2009; Rendall et al., 2009; Ekert-Jaffé et al., 2002) and has not fully investigated the biases introduced from the selection of this select sample. However, work on post-census linkage exercises has highlighted differing trends by age group and sex for the linkage of LS members between census dates (Blackwell et al., 2003; Hattersley and Creeser, 1995). Such findings have often been disregarded; insufficient attention has been paid to the systematic trends in the linkage of LS members from one census to the next.

Recent attention has focused on the fertility of recent migrants into the UK (Tromans et al., 2009). Such migrants would be ignored if fertility analyses were based on the sample who are continually resident between census dates. However, selecting a sample from the LS to include new entrants between 1991 and 2001 requires care because there are some LS members for whom there is incomplete information on their residence between census dates. This article tackles the issue by taking an alternative approach which seeks to attribute exposure to risk to all LS members in the 1991-2001 period. Through developing residence trajectories it is possible to define LS members as one of two types of case. Consistent cases are where LS members display a residential history in the LS which is internally consistent in that the sequence of events provides a potentially 
complete residential history throughout the intercensal period. Inconsistent cases consist of LS members for whom there is at least one piece of event information missing or an incoherent sequence of events (for example a recorded exit from the study, no record of a re-entry and then residence at the subsequent census).

In this article we estimate fertility rates for England and Wales between 1991 and 2001 using the consistent cases. These include the continuously resident members, as well as those who enter into and exit from the LS during the intercensal period. As a further check we compare the resulting sample of women with ONS mid-year population estimates and the resulting sample of births with the number we would expect given the number of births registered within ONS vital registration. In so doing we demonstrate the impact of including non-continuously resident women on the denominator and numerator used for calculating fertility rates.

\section{Data and methods}

The method used has three stages:

1. The identification of two main forms of resience trajectory - consistent and inconsistent cases.

2. The calculation of age-specific fertility rates (ASFRs) for samples of consistent and inconsistent cases.

3. The calculation of rates of representation which compare women and births used to calculate the ASFRs with the corresponding ONS mid-yea r population estimates and vital registration birth numbers.

\section{Devising residence trajectories}

Given the information available on the residence of LS members in the intercensal period it is possible to devise hypothesised forms of residence trajectory which female LS members took between the 1991 and 2001 censuses. Using the information recorded on new entries to the study, embarkations from the study and re-entries it is possible to quantify the number of members taking different trajectories and identify the LS members who were resident in a particular calendar year.

The two types of trajectory are:

a) Consistent cases - LS members for whom there is an internally consistent sequence of events providing a coherent story on residence through the intercensal period.

Within the consistent cases there are two possible forms of residence:

1) Continually resident cases - cases where there is no recorded embarkation or re-entry;

2) Non-continually resident cases - cases where there is an exit from and/or entry to the study in the intercensal period.

b) Inconsistent cases - LS members where there is at least one piece of event information missing or an incoherent sequence of events. 
This article is primarily concerned with reporting on the consistent cases as they are by far the most numerous in the LS and provide a coherent and complete story. The total number of LS members enumerated at the 1991 Census and the 2001 Census are used as benchmarks. These can be used to classify the consistent cases into those who were existing members of the LS in 1991 and those who entered after 1991 and had not previously been LS members.

\section{Consistent LS members - existing members}

Nine forms of consistent residence have been developed for those who joined the LS before or at the time of the 1991 Census. The forms of residence are shown in Figure 1.

Continuously resident cases:

Type 1 - LS members resident at the 1991 and 2001 censuses with no recorded embarkation between 1991 and 2001.

Non-continuously resident cases:

Type 2 - LS members resident at the 1991 Census who died in the 1991-2001 period (there was no embarkation or re-entry to the LS in this period).

Type 3 - LS members resident at the 1991 Census, who embarked, re-entered and then died before the 2001 Census.

Type 4 - LS members resident at the 1991 Census and making an embarkation. They were not present at the 2001 Census.

Type 5 - LS members resident at the 1991 Census, embarking and re-entering before making another embarkation and not returning before the 2001 Census.

Type 6 - LS members resident at the 1991 Census and making an embarkation and re-entry in the decade before being resident at the 2001 Census.

Type 7 - LS members not at the 1991 Census but who were part of the LS at an earlier date and re-entered in the 1991-2001 period and were then resident at the 2001 Census.

Type 8 - LS members not present at the 1991 Census, who re-entered in the 1991-2001 period, and died before the 2001 Census.

Type 9 - LS members not present at the 1991 Census, who re-entered in the 1991-2001 period and then embarked before the 2001 Census.

Consistent LS members - new entrants

People registering at a GP with an LS birth date enter the LS in the intercensal period. Six trajectories have been created for new entrants into the LS. The criterion is that the LS member entered the LS for the first time in the 1991-2001 period. Figure 2 shows the hypothesised residence trajectories for these LS members. 
Non-continually resident consistent cases:

Type 10 - LS members who entered between 1991 and 2001 and were continually resident thereafter and at the 2001 Census.

Type 11 - LS members who entered the LS between 1991 and 2001 and died between the entry date and the 2001 Census.

Type 12 - LS members who entered the LS between 1991 and 2001, then embarked and reentered before 2001 and were recorded at the 2001 Census.

Type 13 - LS members who entered the LS between 1991 and 2001, then embarked and reentered and died before the 2001 Census.

Type 14 - LS members who entered the LS between 1991 and 2001, embarked, re-entered and then re-embarked and were not at the 2001 Census.

Type 15 - LS members who entered the LS between 1991 and 2001, then embarked with no re-entry to the LS before the 2001 Census.

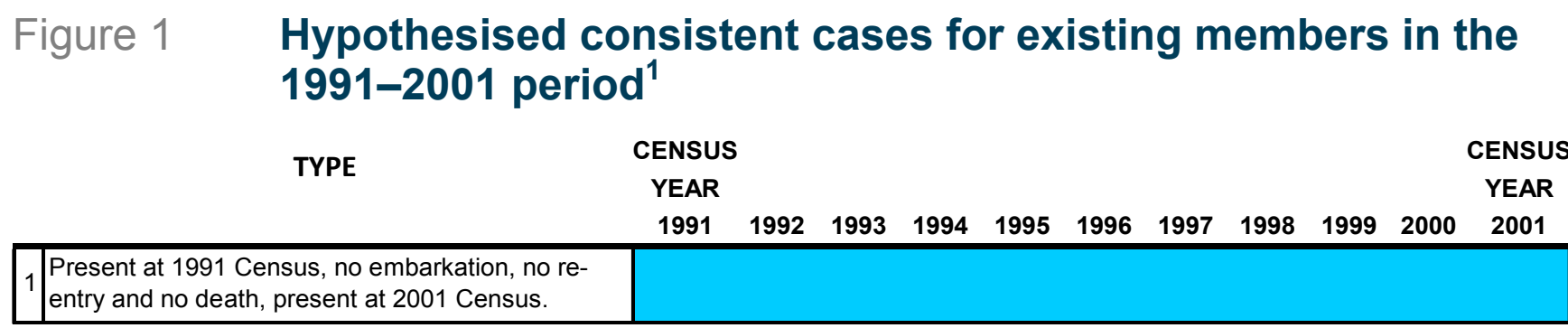

2 Present at 1991 Census, death, not at 2001 Census

3 Present at 1991 Census, embarkation, re-entry and

3 death, not at 2001 Census.

4 Present at 1991 Census, embarkation, no re-entry,

4 no death, not at 2001 Census.

\begin{tabular}{|l|l|l|l|l|}
\hline 5 & $\begin{array}{l}\text { Present at } 1991 \text { Census, embarkation, re-entry, } \\
\text { embarkation, not at } 2001 \text { Census. }\end{array}$ & & & \\
\hline
\end{tabular}

6 Present at 1991 Census, embarkation and re-entry,

6 present at 2001 Census.

7 Not present at 1991 Census, re-entry recorded, at

72001 Census.

8 Not present at 1991 Census, re-entry recorded,

death and not at 2001 Census.

\begin{tabular}{|l|l|l|l|l|}
\hline 9 & $\begin{array}{l}\text { Not present at } 1991 \text { Census, re-entry recorded, } \\
\text { embarkation and not at } 2001 \text { Census. }\end{array}$ & & & \\
\hline
\end{tabular}

Included in the LS and 'exposed to risk of birth'

1: Note that events by year in the sequence are hypothetical

Source: Robards (2010) 


\section{Figure 2 Hypothesised consistent cases for new entrants into the LS in the 1991-2001 period $^{1}$}

TYPE

10 Entry between 1991 and 2001 census, no embarkation, no re-entry, no death, present at 2001 Census.

11 Entry between 1991 and 2001 census, no embarkation, no

11 re-entry, death, not present at 2001 Census.

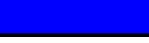

12 Entry between 1991 and 2001 census, embarkation and re2 entry, no death, present at 2001 Census.

13 Entry between 1991 and 2001 census, embarkation and reentry, death, not present at 2001 Census.

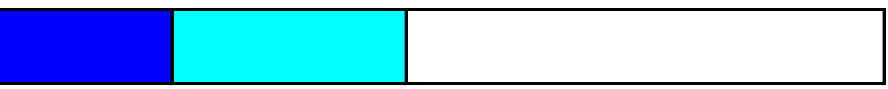

14 Entry between 1991 and 2001 census, embarkation and re-

14 entry, embarkation and not present at 2001 Census.

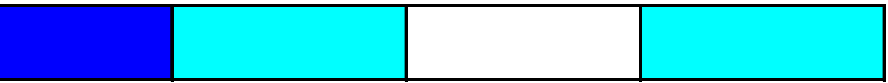

15 Entry between 1991 and 2001 census, embarkation, no re-

15 entry, no death, not present at 2001 Census.

Included in the LS and 'exposed to risk of birth'

Time before entry into the LS, denotes time outside of the LS

1: Note that events by year in the sequence are hypothetical

Source: Robards (2010).

\section{Calculating ASFRs}

Age-specific fertility rates (ASFRs) show the intensity of fertility. To calculate an ASFR, the number of women of a particular childbearing age in a calendar year must be used as the denominator, and births to women of this age used as the numerator. The number of births in the year to women aged $\mathrm{x}$ is divided by the mid-year population of women aged $\mathrm{x}$ at their last birthday. By multiplying this figure by 1,000 the ASFR per 1,000 of the population is derived. Because the composition of the LS is continually changing in any year an algorithm was written to take into account entries to the LS, exits from the LS and deaths among LS members as of the mid-year (denominator) and the calendar year (births).

The ASFR is defined as:

$$
f x=\frac{\text { births in year } t \text { to women aged } x \text { last birthday at the last time of birth }}{\text { mid-year population of women aged } x \text { last birthday }}
$$

(Hinde, 1998).

\section{Calculating rates of representation}

The ONS LS Development Team calculate linkage rates which are the number of people or events to LS members divided by the corresponding number which are expected to occur in the calendar year. Within demographic literature the term 'linkage rate' normally refers to the ability to link two datasets together rather than the degree to which the population is represented. Therefore we prefer to use the terms 'representation of LS births based on official statistics' and 'representation 
of LS women based on official statistics'. The results from calculating rates of representation show the degree to which the ONS LS is accurately representing births and certain age groups.

Deviations in the ASFRs can be understood through the separate denominator and numerator comparisons. This identifies whether there is a denominator or numerator bias in the LS and whether this is particularly the case for some age groups. Biases can arise either because of too few or too many births are counted in the numerator or too few women or too many women are included in the denominator.

The representation of LS women and births is calculated by:

1. Establishing the 'expected' number of births or number of women in the LS by dividing 4 (the number of birth dates used in the LS) into 365.25 (average number of days of the year inclusive of leap years) and then multiplying this by the England and Wales births or number of women figure for the relevant age group.

2. Dividing the number of LS births or number of women by the 'expected' number in the LS.

\begin{tabular}{|c|c|c|c|}
\hline & & 4 & \\
\hline in the LS & & 365.25 & births / women \\
\hline
\end{tabular}

Representation of LS

births/women based = $\quad=\quad$ LS births $/$ women

on official statistics $\quad$ Expected births / women in the LS

The next section presents the key findings.

\section{Findings}

First we describe the proportion and characteristics of LS members present at 2001 for the consistent cases. We then proceed to calculate ASFRs for these consistent cases, comparing the findings for all consistent cases as opposed to the subset who were continuously resident between 1991 and 2001. Rates of representation for LS women and births for these groups are reported at the end of this section.

\section{Consistent case residence trajectories 1991-2001}

Most LS members at the 1991 Census had consistent residential histories in the 1991-2001 period and the majority of these consistent cases were continuously resident. For the 1991-2001 period, 89 per cent of all LS members present at the 1991 Census and aged under 55 years, had consistent residential histories and 87 per cent were continuously resident (Table 1). The smallest percentage of consistent cases occurs among those aged 10-19 years in 1991 (about 84 per cent). Of those consistent cases who were not continuously resident, the most numerous are Type 2 , who died during the intercensal period (which reflects their older age profile). Adding the noncontinuously resident cases to the analysis increases the female sample for analysis across the whole decade by around 13,000 members. 
Table $1 \quad$ Number of LS members by type, resident at the 1991 Census

\begin{tabular}{|c|c|c|c|c|c|c|c|c|c|}
\hline \multicolumn{9}{|c|}{ CONSISTENT CASES AT 1991 CENSUS } & \multirow{3}{*}{$\begin{array}{c}\% \\
\text { INCONSISTENT } \\
\text { CASES (AT } 1991 \\
\text { CENSUS) }\end{array}$} \\
\hline \multirow{2}{*}{ Age at 1991} & \multirow{2}{*}{$\begin{array}{l}\text { LS members at } \\
1991 \text { Census }\end{array}$} & \multicolumn{7}{|c|}{ \% Existing members } & \\
\hline & & Type 1 & Type 2 & Type 3 & Type 4 & Type 5 & Type 6 & Total & \\
\hline $0-4$ & 14,952 & 87.4 & 0.1 & * & 0.4 & * & 0.1 & 88.1 & 11.7 \\
\hline $5-9$ & 16,625 & 87.1 & 0.1 & * & 0.3 & * & 0.1 & 87.6 & 12.3 \\
\hline $10-14$ & 16,098 & 83.3 & 0.2 & $*$ & 0.3 & * & 0.1 & 84.0 & 15.8 \\
\hline 15-19 & 16,483 & 82.6 & 0.3 & * & 0.3 & * & 0.2 & 83.5 & 16.3 \\
\hline $20-24$ & 19,761 & 84.5 & 0.4 & $*$ & 0.7 & 0.0 & 0.3 & 86.0 & 13.5 \\
\hline $25-29$ & 21,276 & 86.5 & 0.5 & $*$ & 0.7 & 0.0 & 0.2 & 87.9 & 11.6 \\
\hline $30-34$ & 19,929 & 88.3 & 0.8 & $*$ & 0.6 & * & 0.2 & 89.9 & 9.9 \\
\hline $35-39$ & 18,168 & 89.0 & 1.3 & $*$ & 0.5 & 0.0 & 0.1 & 91.0 & 8.9 \\
\hline $40-44$ & 19,507 & 89.8 & 1.9 & * & 0.3 & * & 0.1 & 92.1 & 7.8 \\
\hline $45-49$ & 17,707 & 89.3 & 3.1 & $*$ & 0.2 & * & 0.1 & 92.7 & 7.2 \\
\hline $50-54$ & 14,526 & 87.9 & 4.4 & $*$ & 0.3 & * & 0.0 & 92.6 & 7.3 \\
\hline Total & 195,032 & 86.9 & 1.2 & $*$ & 0.4 & 0.0 & 0.2 & 88.7 & 11.1 \\
\hline
\end{tabular}

Source: ONS LS July 2010 / January 2011

Note: * denotes values have been deleted to meet ONS disclosure controls.

Among LS members present at the 2001 Census the percentage of consistent cases was 92 per cent and of continuously resident cases 88 per cent (Table 2). The percentages of continuously resident cases (Type 1) are lowest among those aged 25-34 years in 2001. Other existing member types of consistent case are rare. Among the migrant types, new entrants to the LS between 1991 and 2001, those who remained resident and were present at the 2001 Census are substantial (Type 10). Overall, these new entrants make an important contribution to the total number of LS members present at the 2001 Census, particularly in the key child bearing age groups. The Type 10 LS members present at the 2001 Census are relatively high for the 25-29 year age group (10 per cent), and for the 20-24 years age group (7 per cent) and 30-34 years age group (6.4 per cent). Overall, these new entrants make an important contribution to the total number of LS members present at the 2001 Census, particularly in the key childbearing age groups. The percentages of inconsistent cases present at the census are lower than among those resident in 1991, in part because many of the inconsistent cases at the 1991 Census are lost through attrition or non-linkage at the 2001 Census (they are therefore not at the 2001 Census). As was the case with 1991, there are higher percentages of inconsistent cases in the younger age groups.

Table 3 shows the cases which were not resident at either census. These are relatively few and in the case of non-migrants are exclusively formed of previous LS members who re-entered the study after 1991 and embarked again before the 2001 Census (Type 9). The corresponding category for new entrants to the LS (Type 15) has around 1,000 cases for the age groups selected and is the largest category among the new entrants group who were not present at a census. 
Table $2 \quad$ Number of LS members by type, resident at the 2001 Census

\begin{tabular}{|c|c|c|c|c|c|c|c|c|c|}
\hline \multicolumn{9}{|c|}{ CONSISTENT CASES AT 2001 CENSUS } & \multirow{3}{*}{$\begin{array}{c}\% \\
\text { INCONSISTENT } \\
\text { CASES (AT } 2001 \\
\text { CENSUS) }\end{array}$} \\
\hline \multirow{2}{*}{ Age at 2001} & \multirow{2}{*}{$\begin{array}{l}\text { LS members at } \\
2001 \text { Census }\end{array}$} & \multicolumn{4}{|c|}{ \% Existing members } & \multicolumn{3}{|c|}{$\%$ New entrants } & \\
\hline & & Type 1 & Type 6 & Type 7 & Total & Type 10 & Type 12 & Total & \\
\hline $15-19$ & 16,295 & 88.8 & 0.1 & 0.2 & 89.2 & 2.8 & 0.0 & 2.8 & 7.9 \\
\hline $20-24$ & 15,782 & 85.0 & 0.2 & 0.2 & 85.4 & 7.0 & 0.1 & 7.1 & 7.5 \\
\hline $25-29$ & 16,800 & 81.1 & 0.2 & 0.3 & 81.5 & 9.7 & 0.0 & 9.8 & 8.6 \\
\hline $30-34$ & 20,425 & 81.7 & 0.3 & 0.2 & 82.3 & 6.4 & 0.1 & 6.4 & 11.2 \\
\hline $35-39$ & 21,515 & 85.5 & 0.2 & 0.2 & 86.0 & 4.0 & 0.0 & 4.0 & 9.9 \\
\hline $40-44$ & 19,673 & 89.4 & 0.2 & 0.3 & 89.8 & 2.4 & 0.0 & 2.5 & 7.6 \\
\hline $45-49$ & 17,806 & 90.9 & 0.2 & 0.2 & 91.2 & 1.7 & * & 1.7 & 7.1 \\
\hline $50-54$ & 19,005 & 92.2 & 0.1 & 0.2 & 92.4 & 1.0 & $*$ & 1.0 & 6.5 \\
\hline $55-59$ & 17,052 & 92.7 & 0.1 & 0.1 & 92.9 & 0.7 & * & 0.7 & 6.3 \\
\hline $60-64$ & 13,825 & 92.4 & 0.0 & 0.2 & 92.6 & 0.6 & $*$ & 0.6 & 6.8 \\
\hline Total & 178,178 & 87.8 & 0.2 & 0.2 & 88.2 & 3.7 & 0.0 & 3.7 & 8.0 \\
\hline
\end{tabular}

Source: ONS LS July 2010 / January 2011

Note: * denotes values have been deleted to meet ONS disclosure controls.

Table $3 \quad$ Number LS members by type, not resident at a census (1991 or 2001)

\begin{tabular}{|c|c|r|r|r|l|r|r|r|}
\hline \multicolumn{7}{|c|}{ CONSISTENT CASES NOT AT A CENSUS } \\
\hline \multirow{2}{*}{ Age at 2001 } & LS members at & Existing members & \multicolumn{5}{|c|}{ New entrants } \\
\cline { 3 - 8 } & $\mathbf{2 0 0 1}$ census & Type 9 & Total & Type 11 & Type 14 & Type 15 & Total \\
\hline $\mathbf{1 0 - 1 4}$ & 17,741 & 14 & 14 & $*$ & $*$ & 54 & 54 \\
$\mathbf{1 5 - 1 9}$ & 16,295 & 9 & 9 & $*$ & $*$ & 23 & 23 \\
$\mathbf{2 0 - 2 4}$ & 15,782 & 15 & 15 & $*$ & $*$ & 88 & 88 \\
$\mathbf{2 5 - 2 9}$ & 16,800 & 34 & 34 & $*$ & $*$ & 281 & 281 \\
$\mathbf{3 0 - 3 4}$ & 20,425 & 42 & 42 & & $*$ & 252 & 258 \\
$\mathbf{3 5 - 3 9}$ & 21,515 & 47 & 47 & $*$ & $*$ & 124 & 124 \\
$\mathbf{4 0 - 4 4}$ & 19,673 & 31 & 31 & & $*$ & 76 & 79 \\
$\mathbf{4 5 - 4 9}$ & 17,806 & 13 & 13 & 4 & $*$ & 32 & 36 \\
$\mathbf{5 0 - 5 4}$ & 19,005 & 11 & 11 & $*$ & $*$ & 32 & 32 \\
$\mathbf{5 5 - 5 9}$ & 17,052 & 11 & 11 & 3 & $*$ & 22 & 25 \\
$\mathbf{6 0 - 6 4}$ & 13,825 & 17 & 17 & 7 & $*$ & 25 & 32 \\
\hline Total & 195,919 & 244 & 244 & 27 & 12 & 1,009 & 1,032 \\
\hline
\end{tabular}

Source: ONS LS July 2010 / January 2011

Notes: * denotes values have been deleted to meet ONS disclosure controls.

Type 8 and Type 13 are not included because there are no cases.

\section{Age-specific fertility rates from the ONS LS}

This section reports ASFRs for i) all consistent cases, ii) continuously resident cases and iii) noncontinuously resident cases. Non-continuously resident cases are largely composed of new 
entrants to the LS. For comparative purposes ASFR values from the ONS vital registration (FM1) fertility series are used as a benchmark in the analysis.

Figure 3 shows the average ASFR values for the 1991-2001 period for the three samples and the corresponding ONS vital registration values. Fertility rates from the LS for all consistent cases are almost comparable with, although slightly lower than, the ONS values. The fertility rates for consistent cases not continuously resident between 1991 and 2001 are substantially higher in all age groups except the 25-29 years group. The ASFRs plotted in Figure 4 imply a total fertility rate of 1.65 live births per woman for the continuously resident cases, and 2.12 for those who were not continuously resident.

In the 20-24 year age group, the higher rate of fertility among the non-continuously resident cases has a substantial effect on the aggregate rate for all consistent cases and draws the aggregate figure closer to the ONS vital registration ASFR values. Generally, the ASFRs for all consistent cases follow the ONS vital registration profile quite well, though they are rather lower in the 20-24, 30-34 and 35-39 year age groups. The continuously resident cases follow the pattern for all consistent cases except in the 20-24 year age group, but the fertility rates for continuously resident women are invariably slightly lower, and so further from those derived from vital registration.

Figure 4 presents average rates for the decade. There is some variation from year to year during the decade. In general, towards the end of the decade the values for all consistent cases and the continuously resident cases in the 15-19 and 20-24 age groups show an increasing downwards divergence from the ONS vital registration figures. In addition to this downwards bias, in 2000 and 2001 there is more of a difference between all consistent cases and the continuously resident cases than in the other years of the decade.

\section{Figure 3 Consistent cases - Age-specific fertility rates, average for 1991-2001}
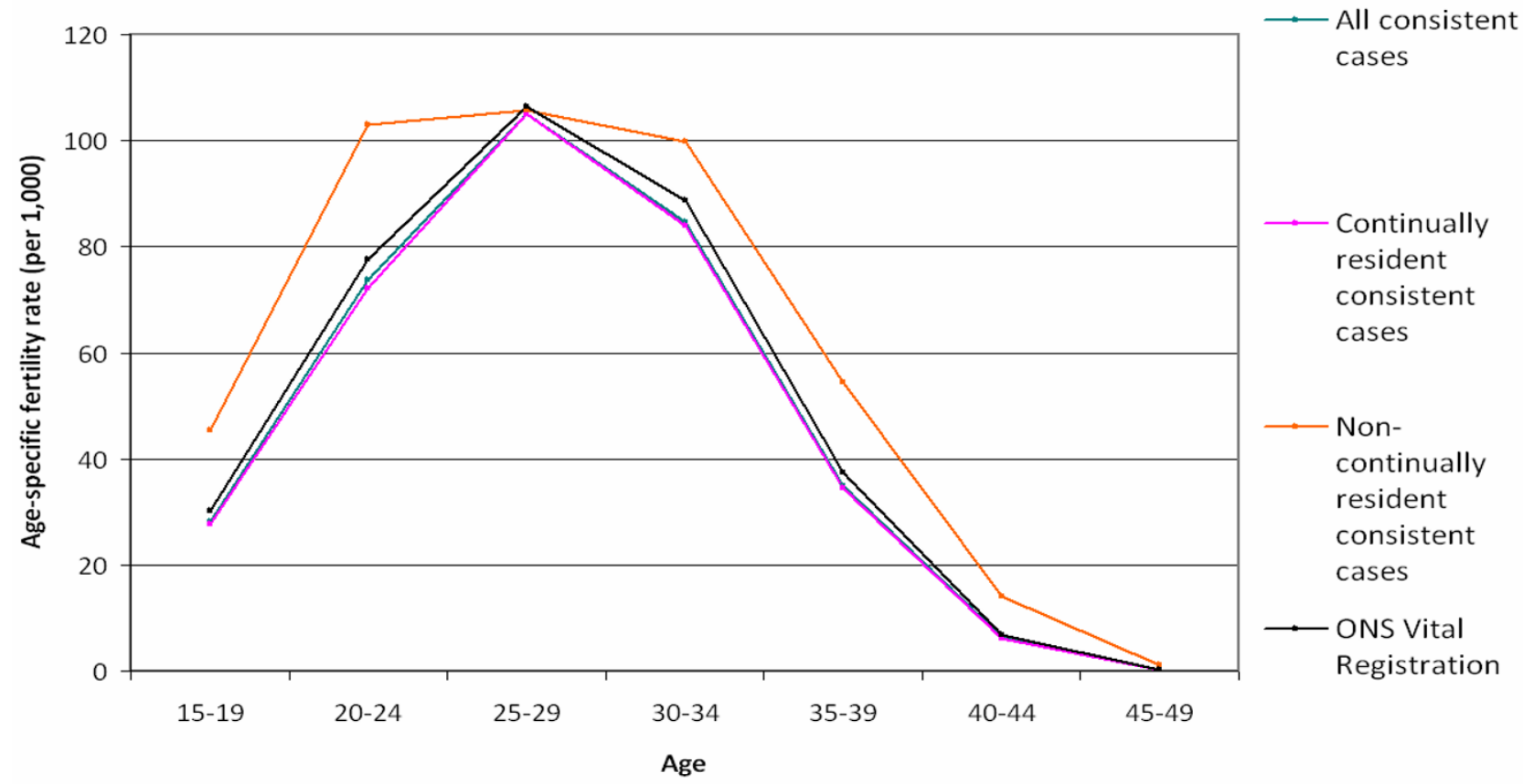

Source: ONS LS, September 2010 and January 2011, FM1 no.30, 2001, September 2010. 


\section{Representation of LS women and births based on official statistics}

This section compares the denominator and numerator used in the above analysis to the ONS midyear population estimates and the ONS vital registration birth numbers. This makes clear the relative representation of the numerator and denominator selected from the LS compared to the corresponding ONS official statistics figures. Where the values for the five year age groups are closer to 1 then the LS is showing a close representation to the corresponding official statistics figures.

\section{Figure 4 Consistent cases - representation of LS women based on official statistics, average 1991-2001}

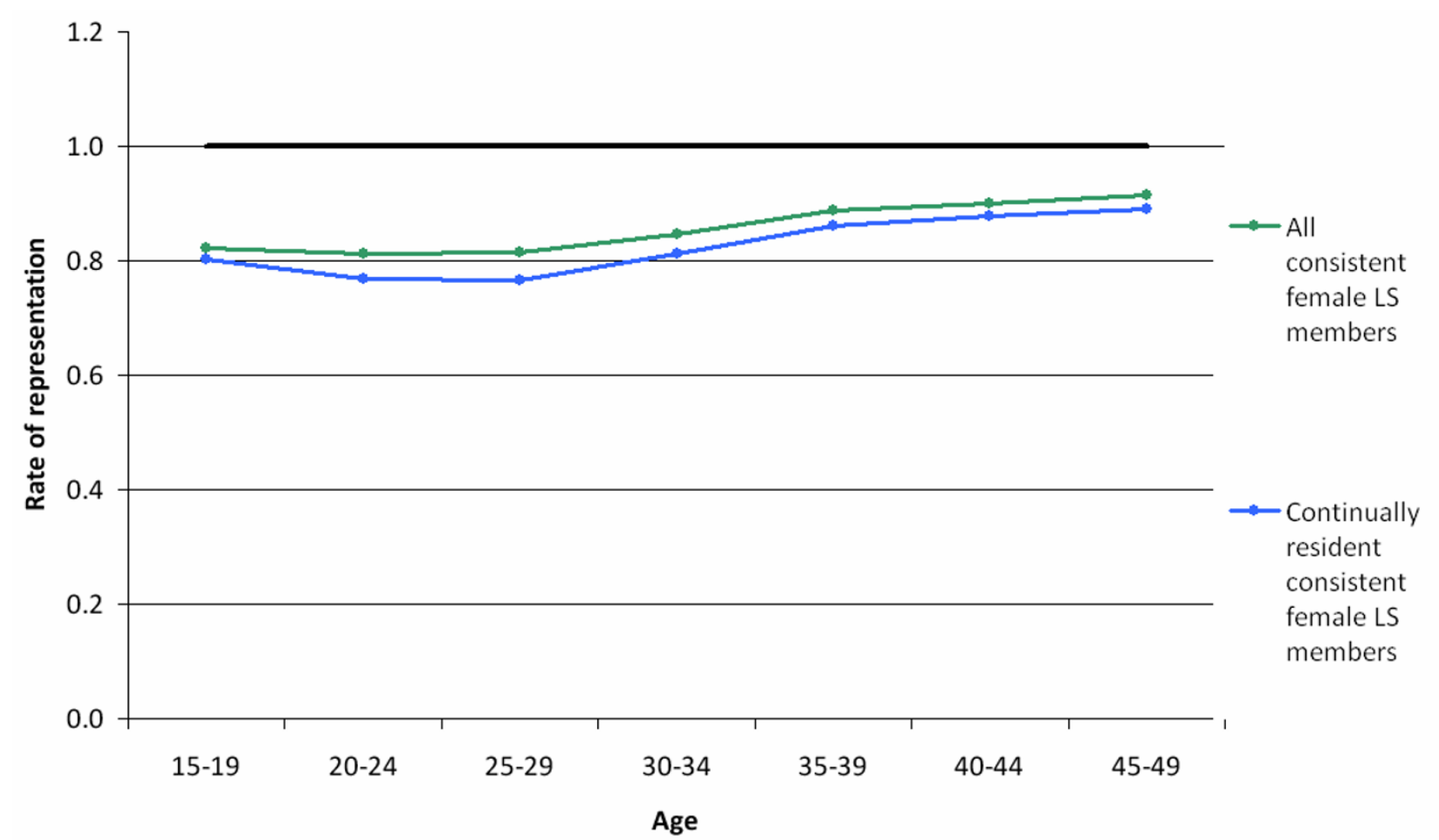

Source: ONS LS, January 2011, ONS Mid-year estimates, Mid-1991 to Mid-2000 Local Authority Population Studies: 07/10/04, ONS Mid-year estimates, Mid-2001 (Revised) Local Authority Population Studies: 09/09/04, Accessed June 2010.

\section{Comparing consistent female LS members 1991-2001 with ONS mid-year population estimates}

Figure 4 shows the representation for the number of LS women of consistent types to the ONS mid-year population estimates for years between 1991 and 2001. The thick black line in Figures 4 and 5 denotes the target rate of representation. Immediately apparent are the lower rates of representation in the younger age groups. For the single years between 1996 and 2001 (not shown) there is a widening gap between all consistent cases and the continuously resident consistent cases. This arises from the non-continually resident consistent cases entering the LS and contributing to the all consistent cases group while the continually resident case numbers start and end the decade with the same numbers. 
For the continually resident consistent cases there seems to be a cohort effect through the decade with low rates in the early part of the decade for the 15-19 and 20-24 year age groups filtering through to the 30-34 year age group at the end of the decade. This is a reflection of the ageing of the cohorts included as of 1991. For the decade as a whole, the only age groups where there is a consistent representation around the target of 1 is the $40-44$ and $45-49$ year age groups. An increase in the representation with age is apparent in the results - the all consistent cases give a better representation with values closer to the target of one.

\section{Comparing births to consistent female LS members 1991-2001 with ONS vital registrations}

The next step is to compare the numerator (births) to LS members with vital registration figures for corresponding years. The sampling of women who are exposed to risk (discussed in the last section) will impact on the births in the LS and the comparison of these to the ONS vital registration official rates.

\section{Figure $5 \quad$ Consistent cases - representation of LS births based on official statistics, Average 1991-2001}

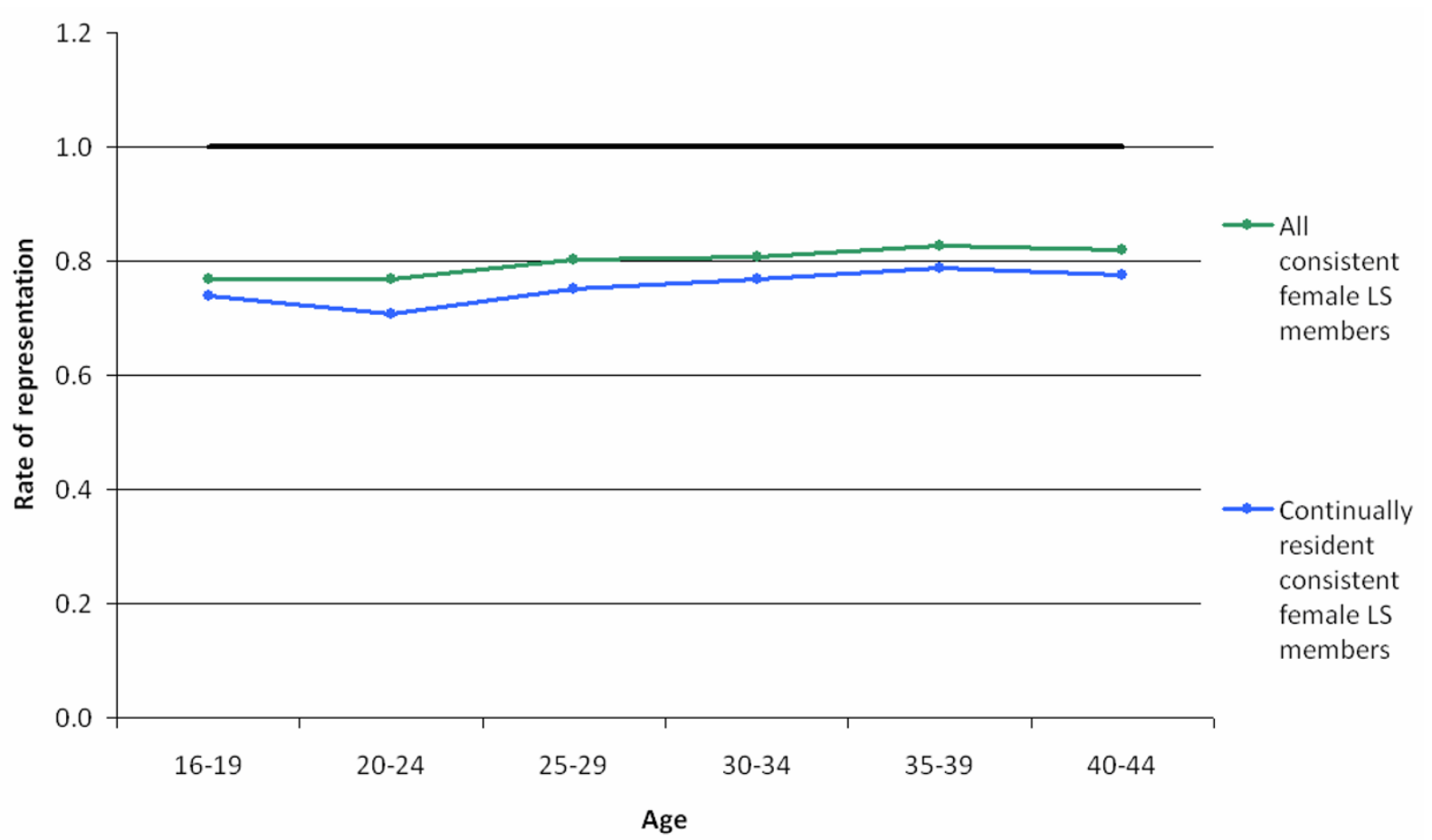

Source: ONS LS, January 2011, ONS FM1 volume - Births: 1938-2004, Maternities, Age of mother, a. all maternities, Accessed June 2010.

Figure 5 shows the average rates of representation for births to consistent cases in the LS between 1991 and 2001. Rates for births to LS members vary more than for women in the LS. There are larger differences between the age groups in the analysis for single years and rates are generally lower than for women in the LS. In general, births to older women in the LS are better represented than for younger ages. Not apparent from the average values in the figure are variations in rates for the 16-19 and 40-44 years age groups for single years. This is likely to be because there are relatively small and changeable numbers of births to LS members in the upper and lower most age groups. Throughout the decade, and especially in the latter part of the decade, 
the all consistent cases category is better at sampling births. Within the 1991-2001 period there is an increasing difference between the all consistent and continually resident consistent cases: this might be related to the new entrants to the LS in the all consistent cases category giving birth, while the continually resident consistent case members consist only of those present starting at the 1991 Census.

\section{Conclusions}

This work has taken an alternative approach to the selection of a sample from the ONS LS for fertility analysis. The residence trajectories devised have allowed the selection and comparison of LS members based on various forms of residence between census dates.

Female LS members in the 1991-2001 period were coded into consistent or inconsistent cases based on their residence characteristics in the intercensal period. Just under 90 per cent of LS members at the 1991 Census fell into the consistent type during the subsequent decade. The noncontinuously resident consistent cases are an important group and an additional 13,000 LS members are added to the sample for analysis through using these types of LS member.

ASFRs for all consistent cases are almost comparable with, although slightly lower than, the ONS values for England and Wales. Fertility rates for members of the study who are continuously resident are significantly lower than for consistent but not continually resident cases. Hence using all consistent cases gives higher ASFRs than is the case when just the continuously resident cases are used.

Rates of representation for LS members continuously resident between 1991 and 2001 were lower than for the all consistent cases. This illustrates that the selection of LS members who are only resident from one census to the next leads to a lower comparability with the target sampling of the LS. The all consistent cases provide a sample from the LS where there is stability in the year-onyear changes in the rates of representation for women compared with the ONS mid-year estimates and the ONS vital registration birth numbers. This analysis has highlighted that the births to noncontinually resident LS members are important in increasing the numerator in the 20-24 and 2529 years age groups.

Overall this article has highlighted that the selection of a sample from the LS for fertility analysis needs careful consideration and the approach of selecting LS members based on their form of residence is beneficial. Non-continuously resident consistent LS members form a sizeable portion of the LS in the 1991-2001 period and show a distinct fertility rate which is easily missed at sample selection stages. 


\section{Key findings}

Typically only females continuously resident in England and Wales between censuses are included in fertility analyses using the LS. The inclusion of cases who are non-continuously resident but who have consistent residential trajectories between 1991 and 2001 adds an additional 13,000 females into the study.

Fertility rates for non-continuously resident consistent women are higher than for continuously resident women. When all consistent cases are selected for the calculation of fertility rates, the age-specific fertility rates are higher than those calculated on a sample restricted to those continuously resident between the 1991 and 2001 censuses. The fertility rates based on all consistent cases are closer to the ONS official statistic figures.

Rates of representation, which compare the number of LS women and the number of LS births with the corresponding ONS mid-year population estimates and vital registration birth numbers, vary across age groups with an improvement in representation at older ages. Rates of representation are improved when all consistent cases are included not just those who are continuously resident.

\section{Acknowledgements}

Comments from two anonymous referees are much appreciated as is the assistance of the Population Trends editorial team. This research has been facilitated by funding from the Economic and Social Research Council (ESRC) (studentship number ES/G018766/1). The permission of the ONS to use the Longitudinal Study is gratefully acknowledged, as is the help provided by staff of the Centre for Longitudinal Study Information \& User Support (CeLSIUS). CeLSIUS is supported by the ESRC Census of Population Programme (Award Ref: RES-348-25-0004). The authors alone are responsible for the interpretation of the data. Census output is Crown copyright and is reproduced with the permission of the Controller of HMSO and the Queen's Printer for Scotland.

\section{References}

Babb P. and Hattersley L. (1992) An examination of the quality of OPCS Longitudinal Study data for use in fertility analysis, LS Demographic Analysis Section, Office of Population Censuses and Surveys, London.

Blackwell L, Lynch K, Smith J. and Goldblatt P. (2003) Longitudinal Study 1971-2001:

Completeness of Census Linkage, Series LS No. 10. Longitudinal Study Unit, Office for National Statistics, London, HMSO.

Ekert-Jaffé O, Joshi H, Lynch K, Mougin R, Rendall M and Shapiro D (2002) 'Fertility, Timing of Births and Socio-economic Status in France and Britain: Social Policies and Occupational Polarization', Population, 53, 475-507.

Goldring S and Newman J. (2010) 'The ONS Longitudinal Study - a prestigious past and a bright future', Population Trends, 139, 4-10. 
Hattersley L and Creeser R (1995) Longitudinal Study 1971-1991 - History, organisation and quality of data, Series LS No. 7. Longitudinal Study Unit, Office of Population Censuses and Surveys, London, HMSO.

Hinde A (1998) Demographic Methods, London, Arnold.

Murphy M (2009) 'Where have all the children gone? Women's reports of more childlessness at older ages than when they were younger in a large-scale continuous household survey in Britain', Population Studies, 63, 2: 115 - 133.

Ní Bhrolcháin M, Beaujouan E and Murphy M (2011) Reported childlessness: a further look at cohort estimates based on survey time-series data, Centre for Population Change Working Paper, Number 11.

ONS (2008) Births to Sample Mothers. See: www.ons.gov.uk/about/who-we-are/ourservices/longitudinal-study/data-quality/event-sampling-and-linkage/births-to-samplemothers/index.html Accessed March 2011.

Portanti M. and Whitworth S (2009) 'A comparison of the characteristics of childless women and mothers in the ONS Longitudinal Study', Population Trends, 136, 10-20.

Rendall M and Smallwood S (2003) 'Higher qualifications, first-birth timing and further childbearing in England and Wales', Population Trends, 111, 18-25.

Rendall M, Ekert-Jaffé O, Joshi H, Lynch K.and Mougin R (2009) 'Universal versus Economically Polarized Change in Age at First Birth: A French-British Comparison', Population and Development Review, 35, 89-115.

Robards J W (2010) 'Calculating fertility rates using the Office for National Statistics Longitudinal Study for England and Wales'. British Society for Population Studies Conference. September 2010. University of Exeter.

Tromans N, Natamba E and Jefferies J (2009) 'Have women born outside the UK driven the rise in UK births since 2001?' Population Trends, 136, 28-42. 